\title{
Cut-Off Values For EEG Frequency in Differentiation of Alzheimer, Non-Alzheimer Dementia and Healthy Subjects: An Application of 3D-ROC Surface Method
}

\author{
Alzheimer Demansı, Diğer Tip Demanshlır ve Sağhlklı Bireylerin Ayrımında \\ EEG Frekansı İçin Cut-Off Değerleri: 3D-ROC Yüzeyi Metodunun Bir Uygulaması \\ Handan ANKARALI, ${ }^{1}$ Seyit ANKARALI, ${ }^{2}$ Fatih Mehmet GÖKÇE, ${ }^{3}$ Şerif DEMIR, ${ }^{3}$ Hulusi KEÇECI' ${ }^{4}$ \\ Departments of ${ }^{1}$ Biostatistics, ${ }^{2}$ Physiology, Medical Faculty of Zonguldak Karaelmas University, Zonguldak; \\ Departments of ${ }^{3}$ Physiology, ${ }^{4}$ Neurology, Medical Faculty of Düzce University, Düzce
}

Submitted / Başvuru tarihi: 26.11.2008 Accepted / Kabul tarihi: 04.03.2009

\begin{abstract}
Objectives: To write a new macro programme for the use of the non-parametric 3-D Receiver Operating Characteristic (ROC) surface method in the discrimination of three or more groups, to study the usefulness of electroencephalography (EEG) frequency in the diagnosis of Alzheimer type dementia (AD), non-Alzheimer type dementia (NAD) and healthy subjects, and to determine cut-off values of EEG frequency.
\end{abstract}

Patients and Methods: The mean EEG frequencies in the left fontal region EEG records of subjects in the present study were calculated and the ROC surface method was used in discrimination of the groups.

Results: The volume under the ROC surface was calculated as $0.464 \pm 0.150$. Accuracy of the mean frequency in differentiation of groups was statistically significant $(p=0.024)$. $8 \mathrm{~Hz}$ was found to be convenient for differentiation of $A D$ from NAD patients and 10 $\mathrm{Hz}$ for the differentiation of NAD patients and healthy subjects. The sensitivity was $87.5 \%$ for Alzheimer's dementia diagnosis and total accuracy was $65 \%$ using this cut-off pair.

Conclusion: We suggest that the mean EEG frequency may be used only as a pre-diagnostic tool for the differential diagnosis of these groups.

Key words: Alzheimer type dementia; dementia; electroencephalography; diagnostic accuracy; volume under a ROC surface; classification.
Amaç: Illk olarak en az üç grubun ayırıcı tanısını yapmak için kullanılabilecek parametrik olmayan ROC yüzeyi metodunun yaygınlaşmasını sağlamak için yeni bir makro programı yazmayı; ikinci olarak bu metotla Alzheimer tipi demans (AD), non-Alzheimer tipi demans (NAD) ve sağlıklı bireylerin ayırıcı tanısında ortalama EEG frekansının kullanılabilirliğini araștırmayı ve üçüncü olarak ortalama EEG frekansına ait cut-off değerleri belirlemeyi amaçladık.

Hastalar ve Yöntemler: Çalışmadaki bireylerin sol frontal bölgesinden kaydedilen EEG örneklerinin ortalama frekansı hesaplanmış ve ROC yüzeyi metodu ile grupların ayırımı planlanmıştır.

Bulgular: Ortalama EEG frekansına göre ROC yüzeyi altındaki hacim 0.464 , bootstrap standart sapması ise 0.150 olarak hesaplanmıştır. Grupları ayırmada ortalama frekansın başarısı istatistiksel olarak anlamlı bulunmuştur $(Z=1.99$ ve $p=0.024)$. Muhtemel bütün değerler arasından en uygun cutoff değerleri sensitivite ve spesifite değerlerine göre belirlenmiştir. Alzheimer tipi demans hastalarını bireylerinden en iyi ayıran değer $8 \mathrm{~Hz}$ iken NAD bireylerini sağlıklı bireylerden en iyi ayıran değer $10 \mathrm{~Hz}$ olarak belirlenmiştir. Bu cut-off çiftinin kullanılması ile $A D$ tanısı için sensitivite $\% 87.5$ ve toplam doğru tanı başarısı \%65 olarak bulunmuştur.

Sonuç: Bulgularımıza dayanarak ortalama EEG frekansının AD diğer demansılılar ve sağlıkı bireylerden ayırmada bir ön tanı aracı olarak kullanılabileceğini önerebiliriz.

Anahtar sözcükler: Alzheimer tipi demans; demans; elektroensefalografi; tanı başarısı; ROC yüzeyi altındaki hacim; sınıflama. 
Diagnostic tests play an important role in the early diagnosis and treatment of diseases. If there is a "Gold Standard" diagnostic test for the diagnosis of the disease, then this test will define the disease in the best way. The diagnostic accuracy will be $100 \%$, but the test may be invasive, postmortem and expensive, or may take a long time. For these reasons, there may be a requirement for non-invasive or cheaper diagnostic tests. If a new diagnostic test becomes available, then the diagnostic accuracy of this test must be evaluated by Receiver Operating Characteristic (ROC) curve analysis. The area under the ROC curve is used as the measure of accuracy in studies examining two groups. ${ }^{[1]}$ In medical studies, subjects are usually classified as one of two basic types which healthy and patient. However, there may be a transitional stage that exists in many disease processes, or more than two groups of disease for differential diagnosis. In these conditions separate ROC curves have often been used for differential diagnosis. [2,3] For example if there are three groups, group 1 and group 2 initially, then group 1 and group 3, and group 2 and group 3 cut-off values from differential diagnosis data are defined with three different ROC curve analyses. This method leads to an increase in type I statistical error. To eliminate such problems, ROC surface analysis was developed. ${ }^{[4]}$

The volume under the surface (VUS) of the ROC surface plot is used as the performance metric. To date studies have focused on the theory of both parametric and non-parametric ROC surface analysis. ${ }^{[4-6]}$ Because ROC surface analysis has not been included in any statistical programme, the use of this method has been limited in practice especially in medical areas. To date only two studies have used a macro programme written for the use of the non-parametric ROC surface method in the diagnosis of three or more groups; one of these studies used Mathematica and the other used the R programme. Furthermore, one of these studies applied parametric ROC surface analysis and the second study applied nonparametric ROC surface analysis when there was verification bias. ${ }^{[7,8]}$ To enable the use of ROC surface analysis in various fields there is a need for new programmes for this type of method.

Dementia is a common progressive disease among the elderly population that is characterized by loss of memory and especially loss of abilities concerning the frontal region. Accounting for approximately two-thirds or more of all dementia cases, ${ }^{[9]}$ Alzheimer's disease (AD) is one of several causes of dementia. Other types of dementia are classified as non-Alzheimer Dementia (NAD). ${ }^{[10]}$ The increasing mean life-span has led to a significant increase in the number of people in the age groups that are at highrisk for developing $\mathrm{AD}$ and NAD.

Preliminary diagnosis of dementia is normally made by a general practitioner on the basis of clinical history of memory impairment and sometimes by using estab- lished techniques such as the Clinical Dementia Rating (CDR) scale. ${ }^{[11]}$ As CDR and various other scales are rater-dependent, time-consuming (involving an interview with at least two people), subjective due to potential unreliable data gathered from the patient or informant, and inapplicable in several situations such as aphasia, deafness or loss of hearing, more simple novel methods should be developed.

Electroencephalography (EEG) is one of the most powerful candidates for this purpose. ${ }^{[12]}$ Electroencephalography has been used for many decades as a non-invasive, cost-effective tool for exploring functional brain changes in dementia. ${ }^{[13]}$ Since gathering information from EEG by both conventional and quantitative methods necessitates experience, special training and expertise, researchers are trying to develop simple methods that can be carried out quickly by a nonspecialist clinician without special training, and that can be used anywhere with a simple EEG recording apparatus, such as electrocardiography.

Although a general slowing in EEG activity has been shown in subgroups of dementia, no changes or differences were found in other studies. ${ }^{[14-17]}$ Conventional visual analyses of the EEG have demonstrated a diffuse slowing of the brain rhythms in AD patients. ${ }^{[18]}$ Some quantitative methods, such as power spectral analysis, have also shown a decrease in the mean frequency with an increase in delta and theta power and a parallel decrease in alpha and beta power in AD patients compared with those of normal elderly subjects. ${ }^{[17]}$ However a cut-off value for EEG frequency as a diagnostic tool has not yet been defined. The exception is a study by Gueguen et al., ${ }^{[19]}$ in which the mean EEG frequencies of normal elderly people and those with $\mathrm{AD}$ were compared and the value of $8.6 \mathrm{~Hz}$ for the mean frequency was determined as the cut-off value for differential diagnosis of normal subjects and AD patients.

The aims of this study were; to write a new macro to perform non-parametric ROC surface analysis in studies that have more than two groups, to evaluate the success of mean EEG frequency as a pre-diagnostic tool using the ROC surface method for differentiation between AD, NAD and healthy subjects and to find cut-off values of mean EEG frequency to differentiate these groups.

\section{PATIENTS AND METHODS}

The study was conducted in Düzce University Research Hospital in Düzce. Eight AD patients (Group 1), sixteen NAD patients (Group 2) and sixteen healthy volunteers (Group 3) were included in the study. Volunteer control subjects were chosen from amongst the patients' companions at the hospital. All AD and NAD patients were randomly selected from the dementia patients who were in follow-up at the neurology outpatient clinic of the Research Hospital of Düzce University. AD patients were diagnosed according to the International 
NINCDS / ADRDA and DSM-IV diagnostic criteria and non-Alzheimer demented patients were diagnosed according to the Clinical Dementia Rating scale (CDR). Mean ages in $\mathrm{AD}$ and NAD groups were $72.0 \pm 10.38$ and $73.2 \pm 8.41$, respectively and the difference was not statistically significant. The following criteria for the control group were established age and sex matched, no disturbances of memory or other cognitive functions, no deficits in the neurological examination, no systemic or other disorders such as diabetes, arterial hypertension, coronary disease, hypercholesterolemia (above $250 \mathrm{mg} / \%$ ), epilepsy, migraine or psychiatric disorders. None of the controls or dementia patients was given neuroleptic, antidepressant or sedative drugs that could affect the results of EEG recordings. Informed consent was obtained from all participants or their caregivers or close relatives, according to the Code of Ethics of the World Medical Association (Declaration of Helsinki) and standards established by the authors' Institutional Review Boards. The study was approved by the ethics committee of the hospital.

\section{Electroencephalography Analysis}

Electroencephalography data were collected by a commercially available system (PowerLab/8sp, AD Instruments, Australia) through an isolated bio-amplifier (BIOamp, ADInstruments, Australia) from the left frontal area. The EEG bio-amplifier was carefully calibrated with checks prior to the recording process in each subject to ensure stability, and precisely the same acquisition parameters and procedures were employed for all individuals included in the study. The pair of electrodes was located according to the international 10-20 system on the scalp F3-F7 points in the left frontal area. We selected this pair because previous studies showed that left frontal regions are greatly affected in dementia. ${ }^{[20,21]}$ Electroencephalography data were recorded in resting state subjects with eyes closed. Subjects were seated in a slightly reclined chair in a sound-attenuated, normally lit room and were kept awake during the recording. In all subjects, EEG recordings were performed for $10 \mathrm{~min}$ utes in the late morning. The bio-amplifier filter setting was set to $200 \mu \mathrm{V} / \mathrm{cm}$ with a high pass value of $1 \mathrm{~Hz}$, a low pass value of $50 \mathrm{~Hz}$ and a sampling rate of $200 \mathrm{~Hz}$. All recordings were stored on a computer and analysed offline. If there was visually detectable blinking or other artifacts these were quickly removed by manual operation. The mean frequency of EEG activity in 10 minutes was measured by the simple data analysis tool of the Chart software and used as the data. Almost all digital EEG recording systems include such analysis tools.

\section{Receiver Operating Characteristic Surface Method}

The Receiver Operating Characteristic (ROC) surface in the three-group case is defined for continuous diagnos- tic markers as a direct generalization of the two-sample ROC curve to three-group classification problems. Two ordered cut-off values named $t_{1}$ and $t_{2}$ are required in order to perform the classification into the three groups. The following decision rule may be applied: ${ }^{[6]}$ $\mathrm{Y}$ is a diagnostic marker. IF $\mathrm{Y}<\mathrm{t}_{1}$ THEN decision is 'group 1'

\section{OR IF $\mathrm{t}_{1}<\mathrm{Y}<\mathrm{t}_{2}$ THEN decision is 'group 2'}

\section{OR decision is 'group 3'}

Different cut-off value pairs for mean EEG frequency were determined for use in differentiation of groups. The most appropriate among these values according to their true classification rates were selected as the optimum cut-off pair $\left(t_{1}\right.$ and $\left.t_{2}\right)$ and the confusion ratio matrix was established according to the optimum pair. This matrix contains the true classification rates and also the rates of misclassification into each of the groups. Three-way ROC surface (3D-ROC) graphic by points whose coordinates are the three true classification rates, over all possible pairs of ordered decision thresholds was drawn. The surface corresponding to a perfect test is the surface of a unit cube.

The volume under the ROC surface equals the probability that diagnostic measurements of any three subjects, one from each group, are in the correct order, and can be a useful index for the accuracy of a three-group diagnostic test. The volume under the ROC surface of $\theta=1 / 6$ corresponds to a test without discriminatory power, and the value of 1 indicates a perfect test. ${ }^{[4,7]}$

The volume under the ROC surface (VUS) is given by, ${ }^{[6,22]}$ VUS $=\hat{\theta}=P\left(Y_{1}<Y_{2}<Y_{3}\right)+\frac{1}{2} P\left(Y_{1}<Y_{2}=Y_{3}\right)+\frac{1}{2} P\left(Y_{1}=Y_{2}<Y_{3}\right)+\frac{1}{6}$ $P\left(Y_{1}=Y_{2}=Y_{3}\right)$

where $Y_{k}$ indicates the test measurement obtained from the $k^{t h}$ group, for $k=1,2,3$. The variance of VUS, $\hat{\theta}$, can be estimated using the Jackknife, Bootstrap or Delta method ${ }^{[23]}$ In this study, the corresponding variance estimator was obtained by using 1000 bootstrap samples. The null hypothesis of the statistical test is:

$H_{0}: \theta=1 / 6$ versus $H_{0}: \theta>1 / 6$, and the $Z$ test was used for this hypothesis.

$$
Z=\frac{\hat{\theta}-\theta}{\sqrt{\operatorname{Var}(\hat{\theta})}}
$$

The 3D-ROC surface method has not previously been included in any statistical package. This is the main reason why this method has not been widely used. For this study we wrote a new macro programme, named HS.MAC, in MINITAB (ver. 14.0) in order to perform the 3D-ROC surface analysis. The non-parametric VUS value and bootstrap variance of VUS were calculated by the HS.MAC programme. In addition, a test was performed for VUS and the appropriate cut-off pairs for the test variable were determined. 
Table 1. Descriptive values of mean EEG frequency $(\mathrm{Hz})$ from left frontal area for each group

\begin{tabular}{lcccc}
\hline Groups & $\mathrm{n}$ & Mean $\pm \mathrm{SD}(\mathrm{Hz})$ & Min. $(\mathrm{Hz})$ & Max. $(\mathrm{Hz})$ \\
\hline $\mathrm{AD}$ & 8 & $5.88 \pm 2.53$ & 2 & 10 \\
NAD & 16 & $8.94 \pm 2.54$ & 5 & 13 \\
Control & 16 & $10.19 \pm 2.69$ & 6 & 13 \\
\hline
\end{tabular}

\section{RESULTS}

Table 1 shows the descriptive statistics as Mean \pm SD for mean EEG frequency values in each group. Based on mean EEG frequency, our estimate of the volume under the ROC surface was 0.464 with a bootstrap standard deviation of 0.150 . The statistical significance of this volume was tested by the $\mathrm{Z}$ test and accuracy of the mean frequency in differentiation of groups was statistically significant $(Z=1.99$ and $p=0.024)$. After this step, all frequency values of the three groups were arranged from large to small and all possible value pairs were taken as the cut-off and the diagnostic accuracy of these pairs was calculated. We selected the optimum cut-off pair according to sensitivity and specificity values. The confusion ratio matrix was established for this pair (Table 2).

In total nine classification rates were calculated on the basis of the optimum cut-off pair for the three groups. Three of these were defined as the probability of correct classification into groups and six were defined as the probability of misclassification. In this study we particularly focused on the correct classification rate for $\mathrm{AD}$ diagnosis and so examined the cut-off pairs of mean frequency that were most powerful for $\mathrm{AD}$ diagnosis. The most appropriate cut-off pair was determined as 8 $\mathrm{Hz}$ and $10 \mathrm{~Hz}$. Of these values $8 \mathrm{~Hz}$ is the cut-off value for differentiation of AD from NAD, and $10 \mathrm{~Hz}$ for differentiation of NAD and control groups. Based on these mean EEG frequency values the probabilities of correct classification of individuals into their groups or incorrect classification into other groups are presented in Table 2. Apart from this cut-off pair, a few other cut-off pairs with high diagnostic accuracy were found, but $8-10 \mathrm{~Hz}$ was selected as the most appropriate and the best diagnostic combination. As shown in Table 2, AD diagnosis success for the selected cut-off pair was high $(87.5 \%)$ and correct classification probabilities of NAD and control individuals were moderate $(56.3 \%$ and $62.5 \%$, respectively). In addition, the individuals who were actually in

Table 2. True and misclassification rates for three groups according to selected cut-off pair (confusion ratio matrix)

\begin{tabular}{lccc}
\hline & \multicolumn{3}{c}{ Predicted } \\
\cline { 2 - 4 } Actual & AD & NAD & Control \\
\hline AD & $7(87.5 \%)$ & $1(12.5 \%)$ & $0(0 \%)$ \\
NAD & $4(25.0 \%)$ & $9(56.3 \%)$ & $3(18.8 \%)$ \\
Control & $3(18.8 \%)$ & $3(18.8 \%)$ & $10(62.5 \%)$ \\
\hline
\end{tabular}

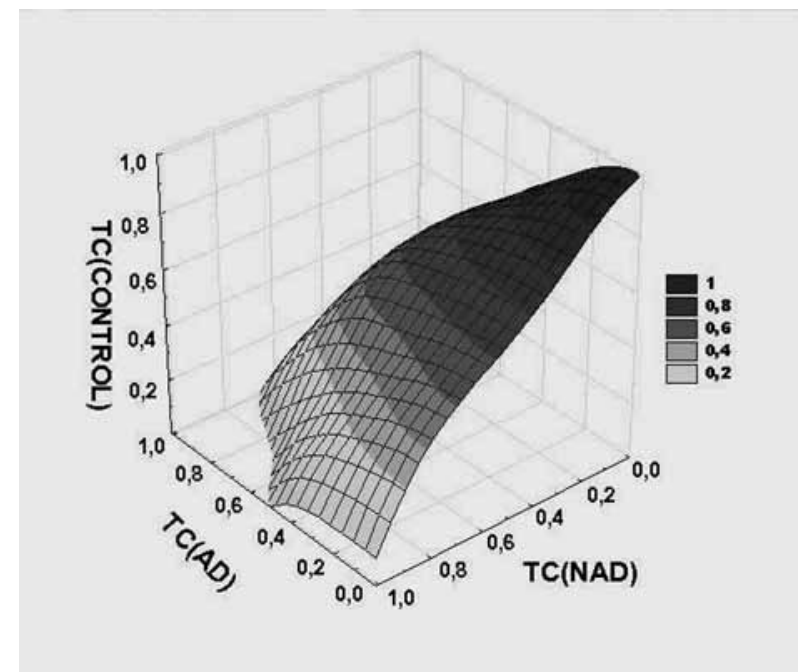

Fig. 1. ROC surface plot for mean EEG frequency, the three axes are the correct classification rates (TC) or sensitivity/specifity values of each cut-off pair for three groups.

the NAD or control group but were placed in different groups on the basis of this cut-off pair were distributed in similar ratios. The total correct classification probability was $(7+9+10) / 40=65 \%$.

Finally the 3D-ROC surface plot was drawn using the true classification rates of all possible cut-off pairs (Fig. 1), and the ROC curves were assessed for the pairwise classification using the true classification rates of the three groups via the non-parametric method (Fig. 2).

\section{DISCUSSION}

Diagnostic methods have been studied intensively in many medical fields. The most widely used and the most informative statistical method for measuring the accuracy of diagnostic tests is ROC analysis. ${ }^{[1]}$ This analysis has been used to differentiate two groups such as patient and healthy groups. When there were more than two groups, some studies also used the ROC curve method, and assessed each pair of groups separately. The weighted area under the curve value was calculated after the areas were obtained with this analysis. This value is a new success criterion. ${ }^{[1,2]}$ However, since only two groups are evaluated in each analysis as if they are independent of the others, type I statistical error will be increased.

Recently, the ROC surface method has been used to diagnose three or more groups, however this method has not yet been widely used. ${ }^{[3,4]}$ The most important reason for this situation is the fact that it has not been included in any statistical software. Only two programmes concerning ROC surface analysis have been reported. The first was written with Mathematica and can perform parametric ROC surface analysis. ${ }^{[8]}$ The second was written with $\mathrm{R}$; in the case of verification bias, nonparametric ROC surface analysis can be performed 
$A D$ vs NAD ROC curve

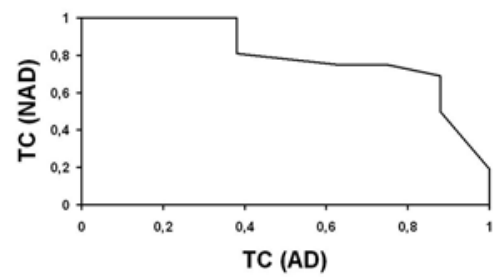

AD vs CONTROL ROC curve

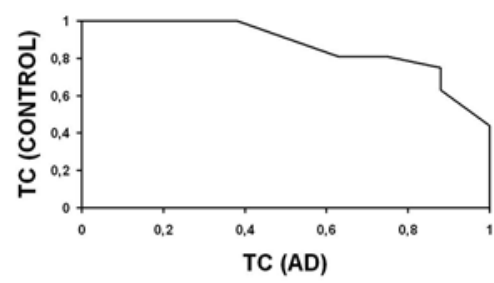

NAD vs CONTROL ROC curve

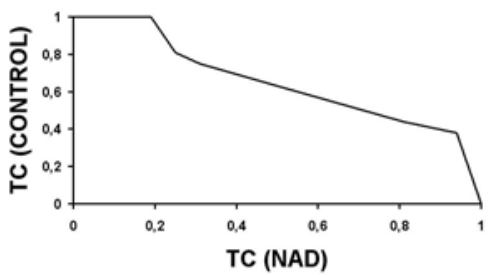

Fig. 2. ROC curves assessing the pairwise classification into three groups. * ${ }^{*} T C$ : True classification rates for $A D, N A D$ and Control groups respectively.

and the standard error of the VUS is predicted using Jacknife and Delta methods. ${ }^{[7]}$

For this study, a Minitab macro programme named HS.MAC was written in order to enable the use of the ROC surface method. Currently, the HS.MAC programme can perform non-parametric ROC surface analysis for only three groups. The bootstrap method is used to predict the standard error of the VUS. Minitab statistical software was chosen to write the macro because it is simple and more commonly used than the Mathematica and $\mathrm{R}$ programmes. Consequently, researchers will be able to use ROC surface methods more comfortably through this macro.

In our study, the usefulness of mean left frontal EEG frequency in pre-diagnosis of $\mathrm{AD}$ and NAD patients in clinical practice was investigated by this method. The role of EEG in differentiation of AD patients from some dementia cases has previously been studied. [12,13,18,24,25] Significant EEG changes were not found in the majority of studies aiming to differentiate vascular dementia and AD. ${ }^{[25]}$ Electroencephalography mapping was shown to correctly diagnose $63 \%$ of cases only. ${ }^{[26]}$ In another study comparing frontotemporal dementia and $\mathrm{AD}$ patients with control individuals separately there was an increase in slow activities in EEG of AD patients but not in frontotemporal dementia patients. ${ }^{[27]}$ These results imply that EEG may be a potential tool for differential diagnosis of AD from various dementing illness. The above-mentioned studies either compared the EEG changes in patients and healthy controls or in two patient groups. In this study, we compared members of three groups simultaneously, and the cut-off values for mean EEG frequency that come from left frontal region EEG records were examined for differential diagnosis.

Since complex and expensive digital EEG recording and analysing systems necessitate highly skilled, trained people, most practitioners and physicians have avoided using EEG in diagnosing and differentiating dementia. In a previous study, the mean EEG frequencies of normal elderly people and $\mathrm{AD}$ were compared and the value of $8.6 \mathrm{~Hz}$ for the mean frequency was determined as the cut-off value in differential diagnosis of normal and AD patients. ${ }^{[19]}$ We determined cut-off values for differentiation of $\mathrm{AD}$ and NAD patients and healthy subjects. In this study, the most successful cut-off value in differentiation of AD and NAD groups was $8 \mathrm{~Hz}$, and for NAD and control groups the cut-off was $10 \mathrm{~Hz}$. The selected cut-off pair provided good accuracy, particularly in AD diagnosis (87.5\%). Total accuracy in assignment of subjects to their groups was $65 \%$ only. This result is concordant with the findings of Saletu et al., ${ }^{[26]}$ who found that mean left frontal frequency could only be used as a pre-diagnostic tool in differentiation of three groups. Because the total correct classification probability was not that high, and because EEG is not a specific tool for dementia diagnosis, mean frequency can only be used as a pre-diagnostic tool in clinical practice. In addition, the number of cases in each group was not large enough to demonstrate that EEG can be used as an advanced differential diagnostic tool.

In actually, the one of important limitations of this study is the number of cases in groups. Because sample sizes in the groups, especial AD group, are small it is impossible to claim that EEG is advanced differential diagnostic tool for dementia.

Mean EEG frequency can be a useful pre-diagnostic tool in differentiation of AD, NAD and healthy individuals. In general, it seems that mean left frontal EEG frequency is lower than $8 \mathrm{~Hz}$ in $\mathrm{AD}$, while it is higher than $10 \mathrm{~Hz}$ in healthy individuals. Electroencephalography is relatively cheap, usable by all practitioners and physicians and available everywhere for AD and NAD diagnosis. The ROC surface method may be an effective tool for differential diagnosis in studies comparing three groups, and the HS.MAC macro that was written for this purpose may be used to compare three groups. Further research with a large number of subjects should be carried out to enable more widespread use of the ROC surface method.

\section{Acknowledgement}

We wish to thank Proof Reading Service for editing this English manuscript.

\section{REFERENCES}

1. Fawcett T. An introduction to ROC analysis. Pattern Recognit Lett 2006;27:861-74.

2. Hand DJ, Till RJ. A simple generalisation of the area under the ROC curve for multiple class classification problems. 
Mach Learn 2001;45:171-86.

3. Everson RM, Fieldsend JE. Multi-class ROC analysis from a multi-objective optimisation perspective. Pattern Recognit Lett 2006;27:918-27.

4. Mossman D. Three-way ROCs. Med Decis Making 1999;19:78-89.

5. Dreiseitl S, Ohno-Machado L, Binder M. Comparing threeclass diagnostic tests by three-way ROC analysis. Med Decis Making 2000;20:323-31.

6. Nakas CT, Yiannoutsos CT. Ordered multiple-class ROC analysis with continuous measurements. Stat Med 2004;23:3437-49.

7. Chi YY, Zhou XH. Receiver operating characteristic surfaces in the presence of verification bias. J R Stat Soc Ser C Appl Stat 2008;57:1.23.

8. Heckerling PS. Parametric three-way receiver operating characteristic surface analysis using mathematica. Med Decis Making 2001;21:409-17.

9. Fratiglioni L, Launer LJ, Andersen $\mathrm{K}$, Breteler MM, Copeland JR, Dartigues JF, et al. Incidence of dementia and major subtypes in Europe: A collaborative study of population-based cohorts. Neurologic Diseases in the Elderly Research Group. Neurology 2000;54(11 Suppl 5):S10-5

10. Evans DA. Estimated prevalence of Alzheimer's disease in the United States. Milbank Q 1990;68:267-89.

11. Lim WS, Chong MS, Sahadevan S. Utility of the clinical dementia rating in Asian populations. Clin Med Res 2007;5:61-70.

12. Soininen H, Partanen VJ, Helkala EL, Riekkinen PJ. EEG findings in senile dementia and normal aging. Acta Neurol Scand 1982;65:59-70.

13. Kowalski JW, Gawel M, Pfeffer A, Barcikowska M. The diagnostic value of EEG in Alzheimer disease: correlation with the severity of mental impairment. J Clin Neurophysiol 2001;18:570-5.

14.Hughes JR, Shanmugham S, Wetzel LC, Bellur S, Hughes CA. The relationship between EEG changes and cognitive functions in dementia: a study in a VA population. Clin Electroencephalogr 1989;20:77-85.

15. Prinz PN, Vitiello MV. Dominant occipital (alpha) rhythm frequency in early stage Alzheimer's disease and depression. Electroencephalogr Clin Neurophysiol 1989;73:427-32.
16. Brenner RP, Ulrich RF, Spiker DG, Sclabassi RJ, Reynolds CF 3rd, Marin RS, et al. Computerized EEG spectral analysis in elderly normal, demented and depressed subjects. Electroencephalogr Clin Neurophysiol 1986;64:483-92.

17. Hughes JR, John ER. Conventional and quantitative electroencephalography in psychiatry. J Neuropsychiatry Clin Neurosci 1999;11:190-208.

18. Jeong J. EEG dynamics in patients with Alzheimer's disease. Clin Neurophysiol 2004;115:1490-505.

19. Gueguen B, Derouesné C, Bourdel MC, Guillou S, Landre E, Gaches J, et al. Quantified EEG in the diagnosis of Alzheimer's type dementia. Neurophysiol Clin 1991;21:35771. [Abstract]

20. Watanabe H, Koike $Y$, Takahashi A, Iguchi H. EEG changes during mental calculation, reverse recitation and association exercises in patients with dementia of the Alzheimer type. Intern Med 1993;32:87-93.

21. Adler G, Brassen S, Jajcevic A. EEG coherence in Alzheimer's dementia. J Neural Transm 2003;110:1051-8.

22. Xiong C, van Belle G, Miller JP, Morris JC. Measuring and estimating diagnostic accuracy when there are three ordinal diagnostic groups. Stat Med 2006;25:1251-73.

23. Agresti A. Inference for two-way contingency tables. In: Agresti A, editor. Categorical data analysis. 1st ed. New York: Wiley; 1990. p.36-78.

24. Ettlin TM, Staehelin HB, Kischka U, Ulrich J, ScolloLavizzari G, Wiggli U, et al. Computed tomography, electroencephalography, and clinical features in the differential diagnosis of senile dementia. A prospective clinicopathologic study. Arch Neurol 1989;46:1217-20.

25. Erkinjuntti T, Larsen T, Sulkava R, Ketonen L, Laaksonen $\mathrm{R}$, Palo J. EEG in the differential diagnosis between Alzheimer's disease and vascular dementia. Acta Neurol Scand 1988;77:36-43.

26. Saletu B, Anderer P, Paulus E, Grünberger J, Wicke L, Neuhold A, et al. EEG brain mapping in diagnostic and therapeutic assessment of dementia. Alzheimer Dis Assoc Disord 1991;5 Suppl 1:S57-75.

27. Lindau M, Almkvist $\mathrm{O}$, Kushi J, Boone K, Johansson SE, Wahlund LO, et al. First symptoms--frontotemporal dementia versus Alzheimer's disease. Dement Geriatr Cogn Disord 2000;11:286-93. 
Copyright of Trakya Universitesi Tip Fakultesi Dergisi / Medical Journal of Trakya University is the property of Trakya Universitesi Tip Fakultesi Dergisi and its content may not be copied or emailed to multiple sites or posted to a listserv without the copyright holder's express written permission. However, users may print, download, or email articles for individual use. 